\title{
Studies on Extraction Behaviour of Cobalt(II) with Nitrobenzoylprazolone-5
}

\author{
Onyedika Gerald $^{\mathbf{1}^{*}}$, Arinze Judith ${ }^{2}$, Ogwuegbu Martin ${ }^{1}$ \\ ${ }^{1}$ Mineral Processing Unit, Department of Chemistry, Federal University of Technology, Owerri, Nigeria \\ ${ }^{2}$ Department of Industrial Chemistry, Abia State University, Uturu, Nigeria \\ Email: "gonyedik@mtu.edu
}

Received December 21, 2012; revised January 28, 2013; accepted February 16, 2013

Copyright (C) 2013 Onyedika Gerald et al. This is an open access article distributed under the Creative Commons Attribution License, which permits unrestricted use, distribution, and reproduction in any medium, provided the original work is properly cited.

\begin{abstract}
The extraction of Cobalt(II) from aqueous solution using 1-phenyl-3-methyl-4-(p-nitrobenzoyl)pyrazolone (HPMNP) in various organic solvents was studied as a function of $\mathrm{pH}$ and extractant concentration. Extraction into organic chloroform phase was more efficient than with any other solvent. The extraction equilibrium constant was found to be $\log \mathrm{K}_{\mathrm{ex}}$ $=-7.04$. Optimum conditions for extraction of $\mathrm{Co}(\mathrm{II})$ exist at $\mathrm{pH}$ of between 5.5 and 7.0, ionic strength of $0.3 \mathrm{M}$ and constant extractant concentration of $0.02 \mathrm{M}$. Shaking the organic $\mathrm{Co}(\mathrm{II})$ chelate complex with $0.2 \mathrm{M}$ acid strips the $\mathrm{Co}(\mathrm{II})$ ions into the aqueous phase. It was established that $\mathrm{Co}(\mathrm{II})$ complex extracted is of composition, $\mathrm{Co}(\mathrm{PMNP})_{2}$.
\end{abstract}

Keywords: Extraction; Solvent; Complex; Pyrazolones

\section{Introduction}

Available reports on solvent extraction methods for cobalt (Co) appear to focus more on the use of organophosphorus compounds or extractants [1-4] and little has been published on the use of pyrazolones; and that is why this study is important. Pyrazolones are prominent analytical reagents [5-8] and potent drugs or pharmaceutical agents [9-12]. The importance of these compounds lies in their ability to form complexes with many metal ions under varied experimental conditions. Of the aroyl pyrazolones, 1-phenyl-3-methyl-4-benzoylpyrazol-5-one (HPMBP) and its substituted analogues have been used as extractants for isolation and separation of various metals [13-15] especially the Group II and transition metals. In our search for various uses of 5-pyrazolones, we have found HPMNP most promising, simple and selective reagent for $\mathrm{Co}(\mathrm{II})$. Extraction studies of metals using this reagent have not appeared widely in the literature. The versatility of HPMNP is comparable to the more popular chelating extratants, HPMBP and Thenoyltrifluoroacetone (TTA), but surpasses them in terms of relative ease of preparation, storage stability and ability to precipitate and extract most metal ions at relatively wide range of $\mathrm{pH}$ values [8,16-17]. The purpose of this study is to investigate the dependency of extraction of

${ }^{*}$ Corresponding author.
$\mathrm{Co}(\mathrm{II})$ on the usual extraction parameters such as $\mathrm{pH}$, extractant concentration and nature of the organic solvents using this reagent, and to determine the possible stoichiometry of the extracted species.

\section{Materials and Methods}

\subsection{Materials}

\subsubsection{Preparation of HPMNP}

The process involved benzoylation of 1-phenyl-3-methyl-pyrazolone-5 (HPMP) with p-nitrobenzoyl chloride, by dissolving HPMP (17.6 g, 0.100 mole) in dioxane (75 $\mathrm{ml}$ ) with gentle warming in a $500 \mathrm{ml}$ three-necked roundbuttom quick-fit flask equipped with a magnetic stirrer, separatory funnel, and a reflux condenser. Calcium hydroxide ( $7.5 \mathrm{~g}, 0.103$ mole) was added dropwise within 2 - 5 minutes (which had been previously dissolved in 50 $\mathrm{ml}$ of dioxane). The mixture was continuously stirred, and gently refluxed for 90 minutes till the yellow calcium complex decomposed by pouring into $400 \mathrm{ml}$ of chilled 3 $\mathrm{M} \mathrm{HCl}$, whereby cream nitro-benzoylpyrazolone-5 separates.

Re-crystallization of the crude product was from an ethanol-water mixture containing a little $\mathrm{HCl}$ to destroy any un-decomposed calcium complex. The crystals are orange-yellow; yield, $86 \%$; and m.pt, $160.5^{\circ} \mathrm{C}$. This method has been adopted by Uzoukwu [18], Meckler [13] 
for the synthesis of other related acylpyrazolones. The reagent exhibits a keto-enol tautomerism and can be obtained in both forms. The orange-yellow enol form was obtained by re-crystallization from heptane or warm ethanol-water mixture, while the colorless keto form was obtained from hot water. No differences in behaviour of these two forms were observed. In the present work, the enol form was used. The HPMP was prepared as recorded by Okafor [19]. Microanalyses for N, H, and C were performed to confirm the purity of the reagent. All other reagents were of analytical grades, and were used without further purification.

\subsubsection{Preparation of Stock Solutions}

Solutions of HPMNP were made by dissolving an appropriate amount of it in organic solvent, so that the stock solution was $0.02 \mathrm{M}$. A Stock solution of $1.7 \times 10^{-3} \mathrm{M}$ $\mathrm{Co}$ (II) was prepared by dissolving $0.48 \mathrm{~g}$ of $\mathrm{CoSO}_{4} \cdot 7 \mathrm{H}_{2} \mathrm{O}$ in $100 \mathrm{ml}$ of $0.1 \mathrm{M} \mathrm{H}_{2} \mathrm{SO}_{4}$. Further dilutions were made from it as required.

\subsection{Methods}

\subsubsection{Extraction Procedures}

To $5 \mathrm{ml}$ of an aqueous buffer solution containing $2 \mathrm{ppm}$ of Co(II) was added $5 \mathrm{ml}$ of $0.02 \mathrm{M}$ solution of HPMNP in chloroform. The two phases were mechanically shaken on a Stuart flask shaker for 60 minutes at $26^{\circ} \mathrm{C} \pm 0.5^{\circ} \mathrm{C}$. Preliminary experiments show that 30 minutes were sufficient for equilibration. For $\mathrm{pH}$ studies, the solutions of $\mathrm{Co}(\mathrm{II})$ were adjusted to different $\mathrm{pH}$ values using chlorides $(\mathrm{KCl} / \mathrm{HCl})$, actate $(\mathrm{NaAc} / \mathrm{HAc})$ and borate buffer solutions to cover $\mathrm{pH} 1$ to 8 . The equilibrated phases were allowed 30 minutes time, and the concentration of $\mathrm{Co}(\mathrm{II})$ remaining in the aqueous phase was determined spectrophotometrically using 1-nitroso-2-naphthol. Hydrogen peroxide was used as the oxidizing agent, followed by extraction with toluene and measuring at 410 $\mathrm{nm}$. The aqueous phase in each case was maintained at a constant ionic strength of $0.3 \mathrm{M}$ with sodium sulphate, $\mathrm{Na}_{2} \mathrm{SO}_{4} \cdot 10 \mathrm{H}_{2} \mathrm{O}$. The $\mathrm{pH}$ values were measured with a digital $\mathrm{pH}$ meter Model HM-208 while a Pye Unicam SP8-100 spectrophotometer was used for spectrophotometric measurements.

\subsubsection{Variation of Extractant Concentration}

$5 \mathrm{ml}$ aliquots of HPMNP of varying concentrations in chloroform were equilibrated with equal volumes $(5 \mathrm{ml})$ of aqueous phase of fixed $\mathrm{pH} 5.5$ (with $\mathrm{NaAc} / \mathrm{HAc}$ buffer) and ionic strength of $0.3 \mathrm{M}$. The solutions were allowed to settle for half an hour in order to separate the phases after which suitable aliquots of the aqueous phase were taken for analysis of $\mathrm{Co}(\mathrm{II})$.

\section{Results and Discussion}

HPMNP is a beta-diketone and exists in both the keto and the enol forms. Figure 1 shows the enol (a) and keto (b) forms of this reagent. The HPMNP enolate ion forms highly extractable metal chelate of the form shown in Figure 1(c), where $\mathrm{n}$ is the charge on the uncomplexed metal ion, and is equal to the number of ligands coordinated to the metal. For the case of $\mathrm{Co}$ (II) being considered, $n=2$. The presence of heterocyclic rings containing
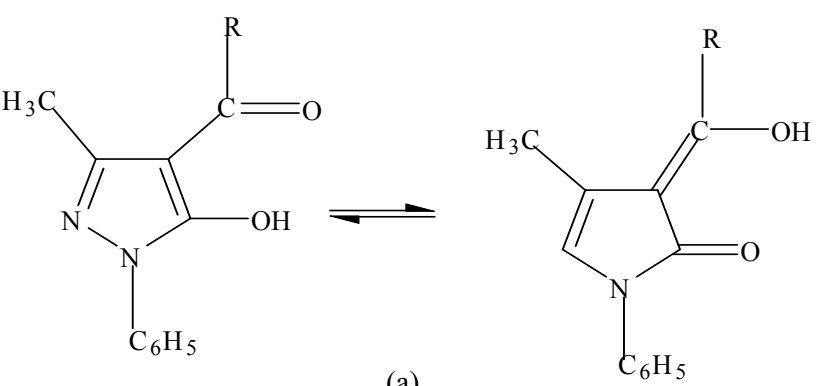

(a)

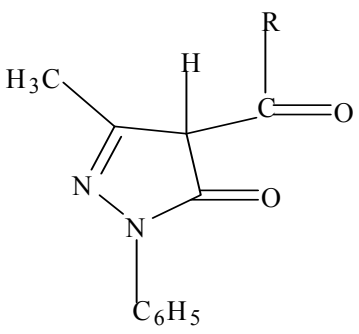

(b)

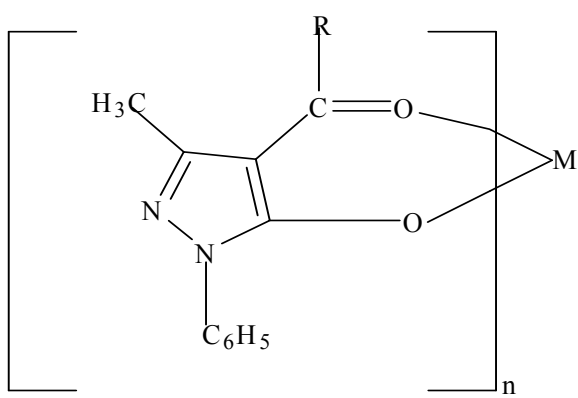

(c)

Figure 1. Keto-enol tautomerism $(\mathrm{R}=$ nitrophenol). 
$\mathrm{N}$ atoms and the nitro groups in the pyrazolone ligands seem to increase the stability of the resulting metal chelates; otherwise, their properties are expected to be paralleled to those of other metal acylpyrazolonates.

\subsection{Effect of pH}

Figure 2 shows the extraction plots obtained by plotting the log of distribution ratio, $\mathrm{D}$ against $\mathrm{pH}$ when HPMNP is dissolved in chloroform. At lower $\mathrm{pH}$ values, the plots are linear with slopes of 1.98 and 2.02 for extractant concentrations of $0.02 \mathrm{M}$ and $0.03 \mathrm{M}$ respectively. The distribution ratio (D) of $\mathrm{Co}$ (II) increased with $\mathrm{pH}$ up to a maximum value of 5.5. Between the $\mathrm{pH} 5.5$ and 7.0, $\mathrm{Co}$ (II) is constantly and quantitatively extracted into the organic phase. The extraction of $\mathrm{Co}$ (II) regressed at higher $\mathrm{pH}$ values where metal hydrolysis is believed to play a dominant role. The slope of approximately 2.0 for the plots indicated that $\mathrm{D}$ is inverse second-power dependent on hydrogen ion concentration of the aqueous phase at room temperature, and that two moles of $\mathrm{H}^{+}$ions were released per mole of $\mathrm{Co}$ (II) ion on formation of an extractable complex (See Equation (3)).

\subsection{Effect of Extractant Concentration}

The data on the variation of extractant concentration is shown in Figure 3 as a $\log -\log$ of D versus extractant concentration. At lower extractant concentrations, straight line of slope $=1$ is obtained, while at higher concentrations up to $0.015 \mathrm{M}$, another straight line with a slope equal to 2.0 is obtained. This means that at higher concentrations, from $0.002 \mathrm{M}$ to $0.015 \mathrm{M}$, two moles of the ligand entered into complexation with one mole of $\mathrm{Co}$ (II) ion to form a 1:2 cobalt-ligand complex; but above 0.02 $\mathrm{M}$ ligand concentration, the extraction is no longer dependent on extractant concentration.

However, the slope of 1.0 at lower HPMNP concentration indicates that one mole of HPMNP is bound to one mole of $\mathrm{Co}(\mathrm{II})$ ion, forming 1:1 complex. Since the plot

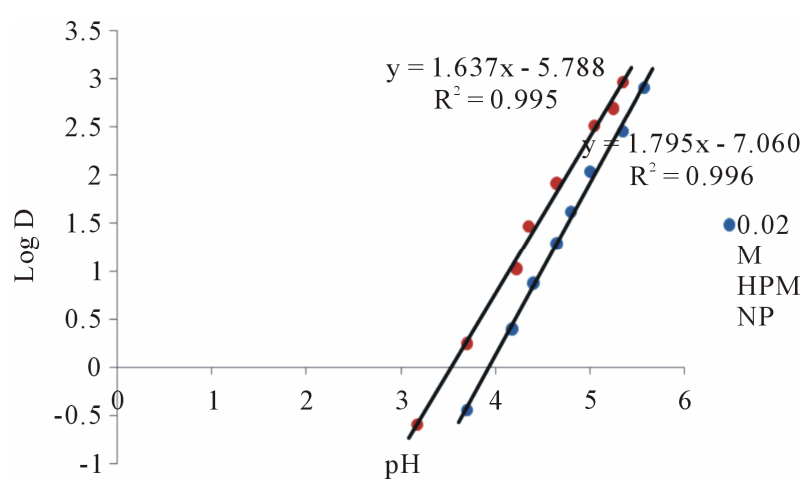

Figure 2. Plot of $\log \mathrm{D}$ (distribution ratio) against the $\mathbf{p H}$ values of the aqueous solution at extractant concentration of $0.02 \mathrm{M}$ and $0.03 \mathrm{M}$.

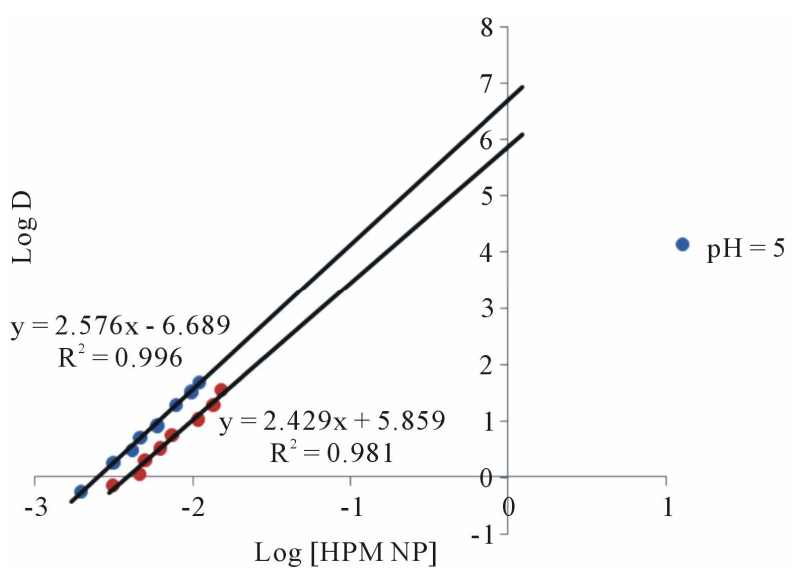

Figure 3. log-log plot of distribution ratio, $\mathrm{D}$ and extractant concentration [HPM NP] in chloroform at pH of 5 and 5.8 .

of $\log$ D against $\log$ (HPMNP) has a slope of 1.0 at lower concentrations and 2.0 between $0.002 \mathrm{M}$ and $0.015 \mathrm{M}$, it, may be assumed that $\mathrm{Co}$ (II) is initially extracted as $\mathrm{Co}(\mathrm{PMNP})^{+}$, and above $0.002 \mathrm{M}$ changes to $\mathrm{Co}(\mathrm{PMNP})_{2}$. It may therefore, be suggested that at low extractant concentrations, $\mathrm{Co}$ (II) forms a charged complex having a 1:1 metal-to-ligand ratio (Equation (1)). This charged complex further reacts with a suitable anion (X) such as acetate present in the buffer solution to form a fairly extractable neutral complex (Equation (2)). These reactions may be represented as:

$$
\begin{gathered}
\mathrm{Co}^{2+}+\mathrm{HPMNP}(\text { org }) \rightarrow \mathrm{Co}\left(\mathrm{PHMNP}^{+}+\mathrm{H}^{+}(\mathrm{aq})\right. \\
\mathrm{Co}(\mathrm{PMNP})^{+}+\mathrm{X}^{-} \rightarrow \mathrm{Co}(\mathrm{PMNP}) \cdot \mathrm{X}(\text { org })
\end{gathered}
$$

The extraction reaction of Co(II) with PMNP at equilibrium may be summarized as,

$$
\begin{aligned}
& \mathrm{Co}^{2+}(\mathrm{aq})+2 \mathrm{HPMNP}(\mathrm{org}) \\
& \rightarrow \mathrm{Co}(\mathrm{PMNP}) 2(\mathrm{org})+2 \mathrm{H}^{+}(\mathrm{aq})
\end{aligned}
$$

from which the extraction equilibrium equation is obtained as:

$$
\log \mathrm{D}=\log \mathrm{K}_{\mathrm{ex}}+2(\mathrm{HPMNP})(\operatorname{org})+2 \mathrm{pH}
$$

The equation is valid for the calculation of the extraction constant, $\mathrm{K}_{\mathrm{ex}}$, the $\log \mathrm{K}_{\mathrm{ex}}$ value from the experimental data using Equation (4) is -7.04. However, the extraction of $\mathrm{Fe}(\mathrm{II}), \mathrm{Cu}(\mathrm{II}), \mathrm{Th}(\mathrm{IV})$, the alkaline earths and the actinides under these conditions is insignificant. This makes it possible for selective separation and isolation of $\mathrm{Co}$ (II) in the presence of these elements [9]. The presence of a nitro group in the extractant is expected to increase the acid properties ( $\mathrm{pka}=3.610 \pm 0.3$ ) and making it more extractive than most of the existing reagents. The extraction of $\mathrm{Co}$ (II) at the higher $\mathrm{pH}$ values is attributed to these properties since $\mathrm{Co}$ (II) cannot be taken as a strong Lewis acid (i.e., a hard acid). 


\subsection{Effect of Organic Solvent}

Figure 4 show the results of the dependency of $\mathrm{Co}$ (II) extraction on organic solvents. Extraction into chloroform gave quantitative results, and followed by benzene and toluene. 0.02 M HPMNP in ethylacetate solution gave only about $60 \%$ extraction. The reagent and its metal complexes dissolve partially or non-at all in most of the usual organic solvents such as carbon tetrachloride, ether, n-hexane, etc. On accounts of these shortcomings, chloroform was used for the study.

\subsection{Effect of Complexing Agents}

The data on the dependency of extraction of $\mathrm{Co}$ (II) on complexing agents show that almost all the complexing agents studied showed minimum interference in the extraction of $\mathrm{Co}$ (II) from aqueous solution under these conditions. The complexing agents investigated included: $\mathrm{F}^{-}$, EDTA, oxalate, $\mathrm{SCN}^{-}$, ascorbate, and citrate ions. The extraction of $\mathrm{Co}$ (II) ions from aqueous solution does not suffer any interference in the presence of fluoride ions. The only appreciable interferences were observed for ascorbate and citrate ions as their concentrations were increased up to $0.75 \mathrm{M}$. In the presence of ascorbate and citrate ions, $72 \%$ and $79 \%$ of $\mathrm{Co}$ (II) ions were respectively extracted. The influence of other complexing agents was intermediate between those of $\mathrm{F}^{-}$and citrate ions. The implication of the above results is that there is no reasonable or complete masking of $\mathrm{Co}$ (II) ions among the reagents studied.

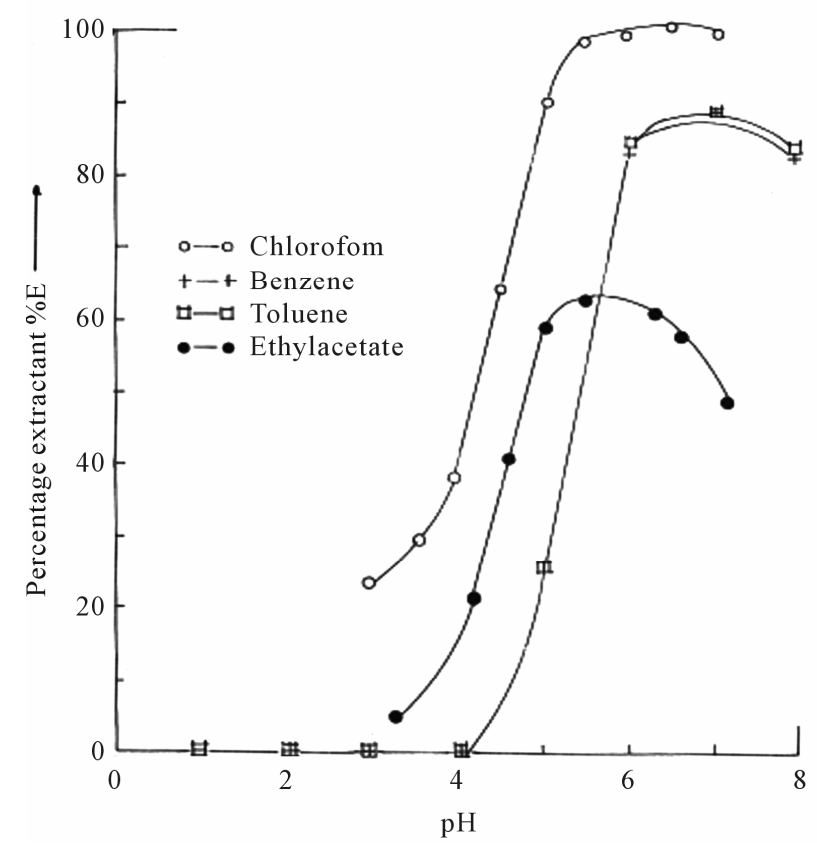

Figure 4. Plot of percentage extractant (\%E) of Co(II) ion against the $\mathrm{pH}$ values of the aqueous solution in various organic solvents $\left(\mathrm{C}_{\mathrm{HPMNP}}=\mathbf{0 . 0 2} \mathrm{M}\right)$.

\subsection{Back Extraction}

Stripping of $\mathrm{Co}$ (II) ions from the organic phase was achieved by shaking the organic phase with an equal volume of $0.2 \mathrm{M}$ mineral acid solution. Complete recovery of $\mathrm{Co}(\mathrm{II})$ was achieved within five minutes.

\section{Conclusion}

The conditions for the formation of extractable $\mathrm{Co}$ (II)extractant complex have been established to exist at $\mathrm{pH}$ range $5.5-7.0$ and extractant concentration of $0.02 \mathrm{M}$. The study suggests that Co(II) ions can quantitatively be separated from aqueous solutions in the midst of other competing metal ions by proper adjustment of the $\mathrm{pH}$. At lower $\mathrm{pH}$ values and extractant concentration where other metals may be quantitatively removed, $\mathrm{Co}$ (II) ions forms non-extractable charged complexes with the ligand. Our study provides a clean and cheap method of purifying and concentrating a material containing cobalt for subsequent electrowinning, if the conditions of the organic and aqueous phases are properly maintained.

\section{REFERENCES}

[1] D. S. Flett and D.S West, "Improved Solvent Extraction Process for Co-Ni Separation by Use of DI(2-Ethylhexyl) Phosphoric Acid (D2EHPA)," In: M. J. Jones, Ed., Complex Metallurgy 78, London, 1975, pp. 49-57.

[2] D. S. Flett and M. T. Anthony, "Cobalt Extractive Metallurgy: A Review," International Journal of Minerals, Metallurgy and Materials, Vol. 1, No. 2, 1998, pp. 299-312.

[3] A. Inove, S. Hatae and M. Kwahara, "The Extraction of $\mathrm{Ni}, \mathrm{Co}$, and $\mathrm{Cu}$ Using Solvent Impregnated Resin-Absorbed LIX 844," Journal of Mineral Processing, Vol. 114, No. 11, 1988, pp. 819-824.

[4] N. B. Devi, K.C. Nathsaram and V. Chakravortly, "Separation and Recovery of $\mathrm{Co}(11)$ and $\mathrm{Ni}(11)$ from Suplhate Solutions Using Sodium Salt of D2EHPA, PC 88A and Cyanex 272," Hydromet, Vol. 49, No. 1-2, 1998, pp. 4961. doi:10.1016/S0304-386X(97)00073-X

[5] S. Diptesh, K. Rishi, S. Ashoke, P. R. Maulik and R. V. Ji, "Stereoselective Alkenylation of a 1,3-Disubstituted Pyrazol-5-One through Ring Transformation of 2H-Puran-2Ones," Terahedron Letters, Vol. 46, No. 22, 2005, pp. 3807-3809. doi:10.1016/j.tetlet.2005.03.207

[6] P. Sarbani, T. Mareddy and M. S. Devi, "High Speed Synthesis of Pyrazolones Using Microwave-Assisted Heat Reaction Technology," Journal of the Brazilian Chemical Society, Vol. 19, No. 6, 2008, pp. 1552-1590.

[7] E. C. Okafor and B. A. Uzoukwu, "Extraction of Fe(III) and U(IV) with 1-Phenyl-3-Methyl-4-Benzoylpyrazolone5," Radiochimica Acta, Vol. 54, No. 4, 1990, pp. $167-$ 172.

[8] D. N. Ekekwe, A. J. Arinze, L. A. Nnanna, C. F. Ukpabia and M. O. C. Ogwuegbu, "Synthesis, Complexation and Characterization of 1-Phenyl-3-Methyl-4-(p-Nitrobenzoyl) 
Pyrazolone-5 and Its Complexes of $\mathrm{Ba}(\mathrm{II}), \mathrm{Sr}(\mathrm{II}), \mathrm{Zn}(\mathrm{II})$," American Journal of Chemistry, Vol. 2, No. 2, 2012, pp. 52-56.

[9] M. O. C. Ogwuegbu and N. C. Oforka, "Solvent Extraction Separation of $\mathrm{Fe}(\mathrm{III}), \mathrm{Co}(\mathrm{III}), \mathrm{Ni}$ (II) and $\mathrm{Cu}(\mathrm{II})$ from Aqueous Solution with 1-Phenyl-3-Methyl-4-(p-Nitrobenzoyl)-5-Pyrazolone," Hydrometallurgy, Vol. 34, No. 3, 1994, pp. 359-367. doi:10.1016/0304-386X(94)90072-8

[10] T. Miyasou, A.-H. Kwon, K. Tsuji, Z. Qiu, T. Okumura and Y. Kamiyama, "Edaravone Prevents Fas-Induced Fulminant Hepatic Failure in Mice by Regulating Mitochondrial BCL-XL and BAX," Shock, Vol. 30, No. 2, 2008, pp. 212-216.

[11] A. Mohamed, G. A. Bou-Rahma and A. Alaa, "Synthesis of Novel Pyrazole Derivatives and Evaluation of Their Antidepressant and Anticonvulsant Activities," European Journal of Medicinal Chemistry, Vol. 44, No. 9, 2009, pp. 3480-3487. doi:10.1016/j.ejmech.2009.01.032

[12] G. Mariappani, B. P. Sala, N. R. Bhuyan, P. R. Bharti and K. Deepak, "Evaluation of Antioxidant Potential of Pyrazolone Derivatives," Journal of Advanced Pharmaceutical Technology \& Research, Vol. 1, No. 2, 2010, pp. 260267.

[13] W. Mickler, A. Reich and E. Uhlemann, "Extraction of Zinc with Long-Chain Diketone," Separation Science and Technology, Vol. 30, No. 12, 1995, pp. 2585-2592. doi:10.1080/01496399508021404

[14] C. Yude, M. Jajum, F. Lei and I. Xinthai, "Study on the
Ternary Synergistic Extraction of U(VI) by Chelating Neutral Extractant," Journal of Radioanalytical and $\mathrm{Nu}$ clear Chemistry, Vol. 108, No. 1, 1986, pp. 41-53. doi:10.1007/BF02165758

[15] M. O. C. Ogwuegbu and F. Chileshe, "Coordination Chemistry in Mineral Processing," Mineral Processing and Extractive Metallurgy Review: An International Journal, Vol. 21, No. 6, 2000, pp. 497-525. doi: $10.1080 / 08827500008914176$

[16] M. O. C. Ogwuegbu, N. C. Oforka and A. I. Spiff, "Enhanced Extraction of Ni(II) with 3-Methyl-4-(p-Nitrobenzoyl)-5-Oxo-Phenylpyrazole in the Presence of Benzyl Alcohol," South African Journal of Chemistry, Vol. 49, No. 1-2, 1996, pp. 26-30.

[17] M. O. C. Ogwuegbu and E. Orji, "Liquid-Liquid Extraction Separation of U(VI) and $\mathrm{Ni}(\mathrm{II})$ by a Substituted OxoPyrazole," Mineral Engineering, Vol. 10, No. 11, 1997, pp. 1269-1278. doi:10.1016/S0892-6875(97)89717-8

[18] B. A. Uzoukwu, "Synthesis, UV-Vis, IR and NMR Spectral Studies of Mn(II) and Zn(II) Complexes of 1-Phenyl3-Methyl-4-(Benzoyl) Pyrazdone-5," Spectrochimica Acta Part A: Molecular and Biomolecular Spectroscopy, Vol. 49, No. 2, 1993, pp. 281-282. doi:10.1016/0584-8539(93)80182-A

[19] E. C. Okafor, "Structure of 1-Phenyl-3-Methyl-4-Benzoylprazole-5-One and Its Derivatives (NMR, IR, etc.)," Zeitschrift für Naturforschung, Vol. 85B, 1980, pp 10191023. 